Verano/Verão 2018

\title{
Biology and ontology: Kant, Fichte, and the uses of natural history
}

Michael Steinberg

\section{(2) OpenEdition \\ Journals}

Electronic version

URL: http://journals.openedition.org/ref/878

DOI: $10.4000 /$ ref.878

ISSN: 2258-014X

Publisher

EuroPhilosophie Editions

Electronic reference

Michael Steinberg, "Biology and ontology: Kant, Fichte, and the uses of natural history », Revista de Estud(i)os sobre Fichte [Online], 17 | 2018, Online since 01 December 2018, connection on 08

September 2020. URL : http://journals.openedition.org/ref/878 ; DOI : https://doi.org/10.4000/ref.878

This text was automatically generated on 8 September 2020

(c) EuroPhilosophie 


\title{
Biology and ontology: Kant, Fichte, and the uses of natural history
}

\author{
Michael Steinberg
}

1 Fichte presents himself as a Kantian, as continuing and developing Kant's transcendental philosophy. Yet at the same time he boasts of presenting something absolutely new, the first philosophy of seeing, the first body of thought which is capable of grasping activity rather than static entities, something so new that it has to have a novel and unique name-Wissenschaftslehre, not philosophy.

2 These claims are not at all incompatible, however, and for Fichte they are in fact the same, because he came to believe-not without justification-that Kant's project was at odds with Kant's way of philosophizing. The critical philosophy could be carried forward only through a radical transformation.

3 I cannot hope to justify such a generalization in a short paper. What I can do is unpack the similarities and differences that are wound around a single, seemingly tangential subject: the two philosophers' arguments from biology.

4 The most extensive discussions of biology in their work both came in the last decade of the eighteenth century, in Kant's Critique of Judgment and in Fichte's System of Ethics and Wissenschaftslehre nova methodo. On first reading the accounts appear extraordinarily similar, and if one encountered them in extracts it might even be hard to tell them apart. For both men the distinctive characteristic of living organisms is their selfperpetuating activity, directed to maintaining their internal structure and thus their continued viability. Their form is a product of their actions and their actions are products of their form, so living beings are both the cause and effect of themselves. ${ }^{1}$ Both also portray the natural world as an interlocking complex of reciprocal and apparently purposeful activity which binds separate and discrete organisms into a biological system. This should not be a surprise, for they were drawing on ideas that were as dominant in the late eighteenth century as neuroscience or evolutionary biology are today. There had been a significant shift in Kant's day towards theories that "vitalized nature," and with this came a strong interest in self-organization and selfgeneration as natural properties. ${ }^{2}$ That shift has often been interpreted as a critical or 
even anti-rationalist responses to a mechanistic bias in Enlightenment thought, but as Jennifer Riskin has recently reminded us, the mechanism of the eighteenth century was less marked off from notions of intentionality and even consciousness than is twentyfirst century physicalism. ${ }^{3}$ The fascination with automata and the later craze for Mesmer show mechanism and purposefulness intermingling, and to think of man as a machine is to admit the possibility that machines, in turn, might possess agency and awareness.

5 But the two philosophers begin to diverge as they move forward. Both invoke the notion of a formative drive that guides and impels self-organization, the Bildungstrieb that features prominently in the writing of Johann Friedrich Blumenbach, Kant, though, praises Blumenbach not so much for his ideas as for his caution in applying them, and interprets the drive as nothing more than the "ability of an organized body to take on ... organization." ${ }^{4}$ Fichte, on the other hand, characterizes the Bildungstrieb as "a drive to form or shape or to cultivate and ... a drive to allow oneself to be formed or shaped or cultivated." It is the distributed activity of the entire system of nature, exhibited both in self-forming and self-maintaining organic wholes and in their reciprocal interactions.

6 There is a far more obvious way in which the two philosophers differ, though. Hardly anything seems less Kantian than a discussion of biology, and biological drives at that, in a System of Ethics. The moral law flies in the face of all inclination, and what are those inclinations but the promptings of our nature as physical organisms? From a Kantian perspective it is hard to see how biology could help us comprehend or comply with a law that is grounded in something utterly apart from our physical being. By incorporating it into his ethical treatise, though, Fichte seems to be moving in just that direction.

7 And what role biology plays for Kant is almost equally problematic. As John Zammito, in particular, has shown, the Critique of Judgment is something of a palimpsest. ${ }^{6}$ Kant's emphasis if not his position changed repeatedly during its composition, and its different layers are not always easy to reconcile. The third critique was meant to complete the critical philosophy, and of course Kant had no need of a fourth; yet how exactly it accomplishes this end is still debated. Worse yet, Kant wrote two introductions to the work and in both he explained his aims, yet those introductions have quite different emphases and focus on different problems.

8 Both, however, shed light on his ambitions. In the first, which has a quasiepistemological focus, Kant explains that the work aims to sanction, though merely as a regulative idea, the concept "that [nature's] arrangement conforms to the ability we have to subsume the particular laws, which are given, to more universal laws, which are not given." We may proceed as if nature were amenable to the systematization of rational thought and theorize as if our theories line up with the underlying order of things, although we cannot assert that homology as a fact.

9 Kant's reserve, though, is slightly disingenuous. Paul Franks has recently argued that the entirety of his critical philosophy responds to the lack of any ultimate grounding to the empirical, which Kant resolves by asserting two orders of explanation and then showing the dependence of the ungrounded order on a supersensual order which is grounded and which has its own, non-theoretical claim to validity. ${ }^{8}$ Interpreters and critics from Jacobi on to the present have seen that this solution depends on Kant's 
ability to show that these two orders are related; as Kant himself wrote in the famous letter to Marcus Herz:

I had said [in the Inaugural Dissertation]: The sensuous representations present things as they appear, the intellectual representations present them as they are. But by what means are these things given to us, if not by the way in which they affect us? And if such intellectual representations depend on our inner activity, whence comes the agreement that they are supposed to have with objects-objects that are nevertheless not produced thereby? And the axioms of pure reason concerning these objects-how do they agree with these objects, since the agreement has not been reached with the aid of experience? ${ }^{9}$

Kant calls this "the key to the whole secret of hitherto still obscure metaphysics..... What is the ground of the relation of that in us which we call 'representation' to the object?" 10

Theoretical reason is reliable as an inquiry into phenomena, so much so that we can agree that it will continue to guide us through all possible experience. But experience of what? If we know nothing but phenomena, how can we know that we are not simply trapped within a compellingly consistent delusion? The first introduction shows that the Critique of Judgment addresses this question, and indeed it does so more comprehensively than Kant's earlier attempts, incorporating biology in a far more subtle way than he did in the relatively straightforward argument from design found in the first Critique's Canon of Pure Reason. ${ }^{11}$

11 In that argument Kant repeatedly invokes teleology. Yet it is not teleology itself which suggests this solution; it is our inability to decide between mechanistic and teleological explanations of organic life. Because we find ourselves with two valid lines of inquiry, we have reason to think that we are interpreting something about which both interpretations are simultaneously true. The very incompatibility of the claims which nature seems to force on us suggests an unknowable perspective which guarantees a harmony or at least a resonance between the order of our thoughts and the noumenal order. As Kant writes, it is through the need for teleological explanation "that reason has a certain suspicion, or that nature gives us a hint, as it were, that if we use the concept of final causes we could perhaps reach beyond nature and connect nature itself to the highest point in the series of causes." ${ }^{12}$

The rich suggestibility of this approach is most evident in sections 76 and 77 of the Critique, which speak of the intuitive intellect or intellectus archtypi. This notion had stood at the apex of the critical philosophy at least since the 1772 letter to Herz. For such an intellect, cognition of objects is at the same time their actualization..$^{13}$ There are no mediating concepts for the simple reason that there is no room for them; the possible and the actual are one and the same, and this intellect is thus all-productive as well as all-knowing. ${ }^{14}$

But the distinction between noumenon and phenomenon is put in danger if we merely bring perceptual form to content which proceeds directly from the intellectus archtypi. The pantheistic implications of the idea that the world is a realization of the divine intellect would be evident even to a lesser thinker than Kant writing at a time other than at the height of the pantheism controversy. Kant is thus pulled in two directions at once. He cannot do without biological purposiveness, but he cannot give teleology any constitutive role without destroying the very argument he is trying to build. $\mathrm{He}$ cannot do without the intuitive intellect, but he cannot grant that we could have any immediate apprehension of that intellect's thoughts even though these might seem to 
be laid out before our eyes as the objects of perception. It is not for nothing, then, that some have interpreted the Critique of Judgment as a text aimed at limiting the damage that theories like Blumenbach's could cause. This risk was clearly evident in Herder, and it is widely granted that significant aspects of Kant's treatment of biology were developed as a critique of his former pupil.

That critique is strongest in sections 72 and 73, in which Kant outlines four possible "systems concerning the purposiveness of nature." He dismisses all four; none of them "accomplishes what it alleges to accomplish." But Kant's dismissal of the third system, the notion of an immanent purposiveness in nature which he labels hylozoism, is especially and tellingly peremptory.

Kant gives two reasons to reject hylozoism. He dismisses the possibility that matter itself might be alive with a wave of his hands:

[W] cannot even think of living matter as possible. (The concept of it involves a contradiction, since the essential character of matter is lifelessness, inertia. $)^{15}$

This is hardly a strong argument. We may well have a concept of matter as lifeless and we may even be compelled to think of it that way, but this says nothing about what matter is in itself or even if there is something to which the concept of "matter" properly applies.

16 Kant also rejects hylozoism because, he insists, any appeal to it is circular. Yet this is not a defect if the circle is a virtuous rather than a vicious one. ${ }^{16}$ What is more, one can see the entirety of the critical philosophy as itself a circular argument that "make[s] trial whether we may not have more success in the tasks of metaphysics, if we suppose that objects must conform to our knowledge." ${ }^{17}$ Kant does not explain why we cannot make a similar trial of hylozoism.

He does not do this, of course, and of the four accounts Kant prefers theism. He begins with faint praise: it too fails, but it does so less than the others. But he soon leaves this caution behind. If this postulate of an intelligent cause, he tells us, "is perfectly satisfactory for all speculative and practical uses of our reason from every human point of view, then indeed I would like to know just what we have lost if we cannot also prove it valid for higher beings, i.e., prove it from pure objective bases (to which unfortunately our powers do not extend)." ${ }^{18}$

Yet this strong and uncharacteristically direct conclusion depends crucially on the rejection of hylozoism. It is thus resting on a very slim reed indeed. It is hard not to conclude that something else is going on here, that Kant's insistence that theism "is based on an indispensable [and] necessary maxim of our judgment" 19 is underdetermined by the arguments presented and correspondingly overdetermined by considerations which he does not acknowledge.

19 I would suggest that what is at work here is nothing inherent in the logic of the critical project in itself, nor is it something derived from Kant's need to maintain the independence of the ethical subject-he does not make that argument in the third Critique and to do so would reduce human individuality to the status of a postulate. It is an ontology to which Kant adhered throughout his career, formed in dialogue with Leibniz and Wolff and passing without essential revision into the critical philosophy. Kant consistently envisioned a universe of real individuals with intrinsic properties, and he saw those individuals as engaged in real interactions, made possible by and carried out in accordance with the inherent properties of a unitary ground. 

Principles of Metaphysical Knowledge" of 1755, whose Proposition XIII reads:

Finite substances by their mere existence are unrelated and are obviously not involved in interaction (commercio) except to the extent that they are maintained by the common principle of their existence, namely, the divine intellect, in a systematic pattern based on mutual relations..$^{20}$

Kant's demonstration of this proposition concludes:

$[\mathrm{T}] \mathrm{o}$ the extent that single substances have an existence independent of others and there is no place for their mutual connections, the least that follow is that it is certainly not the lot of finite things to be the [creative] causes of other substances. Nevertheless, since all things are found assembled in an all-embracing mutual connection, it must be admitted that this relationship depends on mutual participation in a common cause, namely God, the general principle of existence. But as a matter of fact, the mutual relations of these things do not follow simply because God founded their existence; it follows only inasmuch as the schema of the divine intellect which provides for their existence conceives of their existence as correlated and so has established their relationships. ${ }^{21}$

In the "Inaugural Dissertation" of 1770, as well, Kant argues that the principle of the intelligible world is what makes it possible "that a plurality of substances should stand in a relation of interaction." 22

21 A great deal of Kant's thinking changed between 1755 and the first Critique, but Kant did not change his mind about what a proper metaphysics should look like; while the scope of possible metaphysical knowledge is significantly narrower in the critical philosophy, it is knowledge of the same underlying shape of things. One might even say that the critical philosophy aims at nothing less than the generation of that shape; starting from individual experience it leads us to the confidence that an intelligible world exists, that it grounds and connects the phenomena we experience, and that an unknowable agent has ordained and established both.

This is the framework for Kant's practical philosophy, too, which is just as much in need of an ontology as the theoretical philosophy. The Critique of Practical Reason had left a fundamental question unanswered which Kant did not address until the Critique of Judgment, and even there it is something of a latecomer, appearing explicitly only in the second, published introduction, written after what Zammito terms Kant's "ethical turn." "[I]t must be possible to think of nature as being such that the lawfulness in its forms will harmonize with at least the possibility of [achieving] the purposes that we are to achieve in nature according to the laws of freedom," ${ }^{23}$ Kant says. This is his other explanation for the aims of the third Critique, and it demands a much stronger resort to the intelligible. One can imagine a naturalistic explanation for the first homology, but the amenability of nature to ethical transformation is significantly harder to conceive of in naturalistic terms, and in that context Kant's appeal to the divine is perhaps more forgivable. Yet that problem arises only because Kant has always already separated the realms that he now seeks to unite or at least reconcile.

23 Kant does not reject hylozoism, then, because the arguments in its favor are weak. He cannot accept it because it is inconsistent with his fundamental ontological commitments. It recognizes no truly intrinsic properties, only relational ones. It leaves no separation between inner and outer and between the individual and its environment -which, of course, is where idealism moves, Fichte most decisively.

This does not mean that the Kantian distinction between noumenon and phenomenon is lost. What Fichte does is transform Kant, not reject him, and his incorporation of 
epigenetic biology could only succeed after he had worked that transformation. He could not simply usher in what Kant had kept out; to claim a theoretical grasp of the noumenal from the evidence of biology would indeed betray the critical project entirely, as it arguably does with Herder.

Several steps in that transformation may be noted here. First of all, Fichte certainly saw Kant's work as incomplete in that it could not present a unified account of the various faculties of the mind. But Fichte was not merely searching for a more fundamental ground of explanation. He was examining a more fundamental subject. If Kant starts with the question of how our inner representations can refer to external objects, Fichte asks how the separation of inner representations from external objects arises in the first place.

Kant's ontology simply assumes the existence of a subject and a realm of objects, and from the perspective of the Wissenschaftslehre it therefore starts too late. It takes its starting point as a given rather than as the problem that it is. This point is made as concisely as possible in Fichte's notes for his 1812 Lectures on the Theory of Ethics: Kant "already possesses consciousness as something that is familiar. Hence, mere facticity. We do not [proceed] this way," says Fichte. "[We] allow the I and consciousness to first come into being. ${ }^{24}$

This facticity obscures the roots of self-consciousness and the I, and not even Kant's genius can cross the boundary lines drawn in accordance with his ontological assumptions. But it also leaves us with the appearance of a fixed point around which our theories can proceed, and as Fichte wrote at the height of the atheism controversy, "something stable, at rest, and dead can by no means enter the domain of what I call philosophy, within which all is act, motion, and life. This philosophy discovers nothing; instead, it allows everything to arise before its eyes." 25

And what arises before the philosopher's eyes is the noumenal itself, but as activity rather than object. This is another step in Fichte's transformation of the critical philosophy. For Kant the noumenal was the supersensible system of real objects and individuals. For Fichte, on the other hand, the noumenal is not the supersensible itself, as Kant often suggests, ${ }^{26}$ but the activity through which the intelligible will-the only true supersensible-manifests as both experience and its objects. As he notes, Kant "calls ... [the noumenal, which lies at the basis of sensible representations] 'something.' But this is not something that possesses being; ... rather [it is] acting." ${ }^{27}$

For Kant the relationship between noumena and phenomena is one between archetype and instance and the relationship between our theories and the unknowable that we theorize about is fundamentally mimetic. For Fichte the relationship is different. It is that between process and product-but this statement needs immediate clarification, because product and process are not to be distinguished. To quote again from the Wissenschaftslehre nova methodo:

A noumenon lies at the foundation of appearance. More precisely, the entire world is both an appearance and a noumenon. ... The noumenon and the appearance are one and the same thing, merely viewed from two different sides in consequence of the necessary duality of the mind. ${ }^{28}$

That is, the ceaseless activity of the noumenal and the stable phenomena of ordinary perception are identical. Here, as so often, it is easy to see how much Hegel took from Fichte; the famous image of the "bacchanalian whirl" in the preface to the Phenomenology is a poetic expression of the very same thought. 
As different as Fichte's noumenon is from Kant's, however, it is just as resistant to theoretical comprehension. The necessary condition of self-conscious experience, its articulation into I and not-I, renders every experience into a subjective perception of an objective world. Self-awareness itself imprisons us in the phenomenal, placing us in the quandary summed up by Novalis in an epigram that loses much of its sense and all of its wit in translation, "Wir suchen überall das Unbedingte, und finden immer nur Dinge." ${ }^{29}$ Anything that we can think about is eo ipso not the noumenal.

For neither Kant nor Fichte is the noumenal completely inaccessible, however, and for both of them it is practical reason that gives access, not theoretical reason. And yet this marks another Fichtean transformation of Kant. For Kant the one point of contact is the fact of freedom under the moral law. It is something known. For Fichte, by contrast, the noumenal is the very movement that the Wissenschaftslehere directs us to observe, and it is grasped not through discursive thought but through our own embodied activity. It is something felt. ${ }^{30}$

And this brings us, at last, to Fichte's engagement with biology. In some ways its placement in the System of Ethics is not as un-Kantian as it might sound. The discussion forms a significant part of the second large division of the text, which is devoted to a "deduction of the reality and applicability of the principle of morality" and aims to show both "the idea of what we ought to do" "and the substrate in which we ought to approximate the realization of this idea." ${ }^{31}$

3 This recognizably raises the same issue that Kant addresses in the second introduction to the Critique of Judgment, the amenability of the world of experience to ethical transformation. What Fichte does, then, is bring together some of the arguments in Kant's second and third critiques, and there are sound and thoroughly Kantian reasons for integrating them. Where Fichte diverges from Kant is how he resolves this problem. In fact, his transformation dissolves Kant's formulation of the task and constitutes it as a different one.

34 Fichte embraces the epigenetic biology of Blumenbach and shares both the contemporary fascination with self-generation, the inherent irritability and intentionality of matter, and an equally common hydrostatic model of drives. He also interprets the compound notion of the Bildungstrieb so that it embraces both the constitution of self-contained organic wholes and the homeostatic maintenance of those organisms through their reciprocal interactions. ${ }^{32}$ Fichte thus reads the Bildungstrieb as a rendition of the creative activity which unfurls itself as the organized whole of the natural world and as experience itself.

Where epigenetic biology gives Kant a hint of an ordering agency at work, then, it gives Fichte a direct insight into the movement of the noumenal. And this is where Fichte has shifted Kant's problem. Kant had to show that the natural world was amenable to the purposes of the moral law, and he could do this only through an off-stage intelligence. Fichte dissolves the fixity of self and world into movement, and having done so he has to show that this movement tends towards the free self-activity of all of its human instantiations. In other words, the moral law must be implicated in into the movement of the drives.

This transformation of the problem was carried out, it should be noted, through the steps outlined above. By locating the Wissenschaftslehre's inquiry at a point prior to existence of the I Fichte opened the door to conceiving individuals as manifestations of 
a pre-individual activity. He then identified that activity with the noumenal itself. But Fichte would fall back into Kant's problem and indeed into a quasi-Cartesian dualism if the impetus towards self-activity-freedom-does not ground the noumenal; a drive to freedom that is superadded to the complex of natural drives would stand to those drives as Descartes' mind does to body. What is worse, perhaps, is that we would have no reason to conclude that the ends proper to the one could be realized through the others.

It would require at least another paper to show in sufficient detail how Fichte accomplishes this, so a few signposts will have to suffice. Readers of the System of Ethics will recall that the sole guide to the ethical quality of an act is the accompanying feeling, and that this sense of contentment-Zufriedenheit-arises from the harmony of the drives accomplished by the act, which fulfills at once the interests of the natural drive and the ends of freedom as conveyed through the pure drive. ${ }^{33}$ But this is not a synthesis but a reunification or a realization of an inherent unity. As Fichte writes, "All phenomena of the I rest solely upon the reciprocal interaction of these two drives, which is, properly speaking, only the reciprocal interaction of one and the same drive with itself." ${ }^{34}$ It follows, then, that the drive towards absolute self-activity, which is the moral law, must be an aspect of the Urtrieb. As everything in existence is a manifestation of that drive, the moral law must therefore be inherent in nature itself. ${ }^{35}$

From the ordinary point of view morality is opposed to nature, but this appears to be the case only because we cannot help but constitute nature in opposition to the I. From the transcendental perspective this opposition falls away. What we experience as nature is the product of the same activity that we grasp as the moral law. Both manifest the "one life" that Fichte hymns in the conclusion of The Vocation of Man. For Fichte as for Hegel, it is only our way of seeing that blinds us to the fact that the entire world is the revelation of the divine. ${ }^{36}$

It is a pity to stop here, because we are at the very heart of the Wissenschaftslehre and the source of many of Fichte's most challenging insights. But it should be clear enough by now to see what Fichte's employment of his contemporaries' biological ideas says about the tasks he set himself and where those diverges from Kant's.

Kant assumed that perception is a construal of a really existing world which we do not and cannot grasp as it is. In some ill-defined but relevant way, however, the order of those perceptions must line up with the unknowable order of the real. As Kant wrote to Herz, the deepest problem lies in establishing that connection, and Beiser is surely correct to argue that Kant never resolved it to his satisfaction; he was still struggling with it in the Opus Postumum. ${ }^{37}$ This tension between ontological separation and epistemological resonance accounts for Kant's deep ambivalence towards biological purposiveness; though needed to hint at the connections between phenomenal and noumenal, it must be whisked off stage before it suggests that we know the noumenal directly. It is too easily taken for a theory of what organisms are in themselves or as a revelation of the ends of the divine.

41 For Fichte, on the other hand, biology poses no threat. It cannot produce the mirage of a theoretical grasp of the noumenal realm because the noumenal is not a realm to be mapped out but an activity to be observed and felt. Epigenesis is simply one aspect of the movement through which a unitary Absolute flows forth as both objective phenomena and transcendentally structured subjectivity. In the Wissenschaftslehre nova methodo the interweaving of biological purposiveness is thus incorporated into the 
fundamental syntheses of consciousness, united with our own free acting and thinking in an all-productive and all-embracing reciprocity..$^{38}$

In a sense these theories are inversions of one another. In Kant's phenomenal realm individuals vanish in the ceaseless play of causality, while as noumena they subsist and interact through a supersensible ground, their intrinsic properties preserved and coordinated. For Fichte the noumenal is the realm of ceaseless activity, and in it there are none but reciprocal relations. ${ }^{39}$ Individuality is a phenomenon, existing only within the ordinary perspective, and is to be overcome in willing the moral law; it is only through "the disappearance and annihilation of one's entire individuality that everyone becomes a pure presentation of the moral law in the world of sense and thus becomes a "pure I." ${ }^{40}$ We must live not for ourselves but as Reason itself, and ethical life is thus a striving towards the unity-both physical and mental-from which which selfpositing emerges but which it sunders and conceals.

But much remains that is clearly Kantian. The Copernican Revolution is carried out with a vengeance. The noumenal/phenomenal distinction remains and is invoked to maintain the reality of freedom in the face of the mechanistic determinism of the phenomenal. The universalizability demand of the categorical imperative is not just retained, it is embedded in the very structure of the Wissenschaftslehre as a whole; one acts ethically only when one acts in consonance with the inner movement of the whole.

Kant's in-itself, conceived of as an order analogous to but distinct from the order of experience, was far from being a necessity of his system. On the contrary, it was too deeply marked by his pre-critical ontological commitments to fit comfortably into a theory that renounced any ambition of describing the intelligible. It also left an irreconcilable tension between a universalistic morality and the presumptive needs of individuals with unique intrinsic properties. Setting Kant's ontology aside thus did more than allow Fichte to incorporate epigenetic biology into his philosophy. It let him develop Kant's fundamental insights with more coherence and rigor than Kant could. ${ }^{41}$ It opened the door to a transformation of the noumenon/phenomenon relationship, the recognition that perception and subjectivity emerge together, and the discovery of an ethics that is at once universal in its demands and solicitous of individual needs. The means were new, but the ends were recognizably Kant's. There is thus some justice to his claim that Fichte was a better Kantian than was Kant himself.

\section{NOTES}

1. Kant § 64, 5:370, Pluhar 249 .

2. See, e.g., Peter Hanns Reill, Vitalizing Nature in the Enlightenment. Berkeley: University of California Press, 2005.

3. Jennifer Riskin, The Restless Clock: A History of the Centuries-Long Argument over What Makes Living Things Tick. Chicago: Chicago University Press, 2016.

4. $\S 81,5: 424$, Pluhar 311 . There is a vast literature on the relationship between Kant and Blumenbach, much of it centering on the arguments of Timothy Lenoir and the extremely strong 
rebuttals by John Zammito (e.g., "The Lenoir Thesis Revisited: Blumenbach and Kant," Studies in History and Philosophy of Biological and Biomedical Sciences, 43 [2012], 120-132) and Robert Richards ("Kant and Blumenbach on the Bildungstrieb: A historical misunderstanding," Studies in the History and Philosophy of Biology and the Biomedical Sciences, 31, 11-32 [2000]; The romantic conception of life. Chicago/London: University of Chicago Press, 2002). A full bibliography on this subject would be as long as the present paper.

5. IV:121, 116.

6. John Zammito, The Genesis of Kant's Critique of Judgment. Chicago: University of Chicago Press, 1992.

7. 20: 202, Pluhar 392.

8. Paul Franks, All or Nothing: Systematicity, Transcendental Arguments, and Skepticism in German Idealism. Cambridge, MA: Harvard University Press, 2005.

9. 10:129 ff., in Kant, Philosophical Correspondence, 1759-1799, trans. Zweig. Chicago: Chicago University Press, 1967, 72.

10. Ibid., 71.

11. A 826, B 854, Kemp-Smith 649: "Purposive unity is ... so important a condition of the application of reason to nature that I cannot ignore it, especially as experience supplies me so richly with examples of it. But I know no other condition under which this unity can supply me with guidance in the investigation of nature, save only the postulate that a supreme intelligence has ordered all things in accordance with the wisest ends. ... Moreover, the outcome of my attempts [in explanation of nature] so frequently confirms the usefulness of this postulate, while nothing decisive can be cited against it, that I am saying much too little if I proceed to declare that I merely hold it as an opinion. Even in this theoretical relation it can be said that I firmly believe in God."

12. $\$ 72$, AK 390, Pluhar 271.

13. As Eckart Förster shows, while its interweaving with a related concept, that of an intuitive understanding of the whole, may blur this point, Kant clearly points toward "a non-sensible, i.e. intuitive intuition for which possibility (thinking) and actuality (being) coincide." Förster, The Twenty-Five Years of Philosophy. Cambridge, MA: Harvard University Press, 2012, 145.

14. $§ 76,5: 402$, Pluhar 284; § 77 passim.

15. $§ 73,5: 394$, Pluhar 276 .

16. See, e.g., Franks, op. Cit., 293. One can hardly avoid mentioning M. A. Abrams, Natural Supernaturalism: Tradition and Revolution in Romantic Literature. New York: W. W. Norton \& Company, 1971.

17. B:xvi, Kemp Smith 22.

18. $§ 75,5: 400$, Pluhar 282 .

19. Ibid.

20. 1:412-413, Beck 100.

21. 1:413, Beck 100-101.

22. 2: 407, Beck 172 .

23. 5:176, Pluhar 15.

24. Lectures on the Theory of Ethics (1812), II/13, 328, Crowe 46. The changes in the theory of the summons from the Foundations of Natural Right to the System of Ethics illuminates just how farreaching this shift is. The first formulation clearly demands an external source for the summons, so that Fichte is eventually reduced to the unsatisfactory expedient of attributing the primordial summons to the first rational individual to God himself in the Garden of Eden. In the System of Ethics, however, the summons is a further moment in self-positing and the summons exists without any mention of a real summoner (SL IV: 219-221, Breazeale 208-210). We ascribe the summons "to an actual being outside of myself," writes Fichte, which is quite different from its actually originating from one. The thrust of the argument, though difficult, appears to be that 
individual self-ascription of free agency is not conceivable without its embeddedness in a complex of interacting free agencies. In other words, the concept of individual free agency is irrational if it is divorced from the concept of a suprapersonal reason; a rational agent in a cosmos of otherwise inert or blindly resistant objects would be neither rational nor free in the Kantian and Fichtean sense. It would be a god, and like all gods could not be self-conscious. The summoner is thus merely posited; in many ways it operates like the Kantian ought.

25. V: 382, Introductions to the WL, 161.

26. WLnm, 131-132, Breazeale 271-272.

27. WLnm, 113, Breazeale 243

28. WLnm, 222, Breazeale, 440 .

29. Blütenstaub § 1

30. Hence the centrality of conscience and the elaborate analysis of states of satisfaction found in SE.

31. SE, IV, 70, Breazeale, 71.

32. See citations in note 4 , supra.

33. For reasons of clarity and space I am omitting the ethical drive.

34. SE, IV, 130, Breazeale, 125. Fichte's claim that there are no morally neutral acts is simply another aspect of this identity.

35. Fichte's writings around the time of the atheism controversy are clearly relevant on the centrality of the "moral image of the world."

36. Hegel, Hegel's Logic: Being Part One of the Encyclopedia of the Philosophical Sciences (1830), trans. Wallace. Oxford: The Clarendon Press, 1975, 274.

37. In Frederick Beiser, German Idealism: The Struggle Against Subjectivism, 1781-1801. Cambridge, MA: Harvard University Press, 2002, 182-185.

38. WLnm, 239, Breazeale, 465. Kant's relation problem appears in Fichte in the deeply ambivalent concept of the Anstoss.

39. "Individual organized wholes are simply products of the organization of the whole universe," WLnm 238, Breazeale 463.

40. SE, IV, 256, Breazeale, 245.

41. This may well be one reason for the success of his ethical theories over those of Kant during much of the nineteenth century, on which see Michelle Kosch, "Fichtean Kantianism in 19thCentury Ethics", Journal of the History of Philosophy 53:1 (2015), 111-132.

\section{ABSTRACTS}

This paper explores the similarities and differences between Kant and Fichte that are wound around a single, seemingly tangential subject: their arguments from biology. The most extensive discussions of biology in their work both came in the last decade of the eighteenth century, in Kant's Critique of Judgment and in Fichte's System of Ethics and Wissenschaftslehre nova methodo. On first reading the accounts appear extraordinarily similar. But the two philosophers begin to diverge as they move forward. Both invoke the notion of a formative drive that guides and impels self-organization, the Bildungstrieb that features prominently in the writing of Blumenbach. Kant, though, praises Blumenbach not so much for his ideas as for his caution in applying them, and interprets the drive as nothing more than the "ability of an organized body to take on ... 
organization." Fichte, on the other hand, characterizes the Bildungstrieb as "a drive to form or shape or to cultivate and ... a drive to allow oneself to be formed or shaped or cultivated." There is a far more obvious way in which the two philosophers differ, though. Hardly anything seems less Kantian than a discussion of biology, and biological drives at that, in a System of Ethics. The moral law flies in the face of all inclination, and what are those inclinations but the promptings of our nature as physical organisms? From a Kantian perspective it is hard to see how biology could help us comprehend or comply with a law that is grounded in something utterly apart from our physical being. By incorporating it into his ethical treatise, though, Fichte seems to be moving in just that direction.

INDEX

Keywords: Blumenbach, Bildungstrieb, biology, Kant, Fichte

\section{AUTHOR}

MICHAEL STEINBERG

Rochester, NY 